\title{
Remote prognosis after primary cesarean delivery: the association of VBACs and recurrent cesarean deliveries with maternal morbidity
}

This article was published in the following Dove Press journal:

International Journal of Women's Health

13 March 2012

Number of times this article has been viewed

\section{Offer Erez' \\ Lena Novack ${ }^{2}$ \\ Vered Kleitman-Meir \\ Doron Dukler' \\ Idit Erez-Weiss ${ }^{3}$ \\ Francesca Gotsch ${ }^{4}$ \\ Moshe Mazor'}

'Department of Obstetrics and Gynecology, Soroka University

Medical Center, ${ }^{2}$ Department of Epidemiology, ${ }^{3}$ Department of Family Medicine, Faculty of Health Sciences, Ben-Gurion University of the Negev, Beer-Sheva, Israel; ${ }^{4}$ Obstetrics and Gynecology Departement, Policlinico GB Rossi Azienda Ospedaliera Universitaria Integrata Verona, Italy
Correspondence: Offer Erez Acting Director, Maternal Fetal Medicine Unit, Department of Obstetrics and Gynecology “B”, Soroka University Medical Center, PO Box I5I, Beer Sheva 84I0I, Israel

Tel +972 8640355 I

Fax+972 86403294

Email erezof@bgu.ac.il
Purpose: To determine the effects of vaginal birth after cesarean (VBAC) versus repeated cesarean sections (RCS) after a primary cesarean section (CS), on the rate of intraoperative and postpartum maternal morbidity.

Patients and methods: This is a retrospective population-based cohort study. During the study period (1988-2005) there were 200,012 deliveries by 76,985 women at our medical center; 16,365 of them had a primary CS, of which 7429 women delivered a singleton infant after the primary CS, met the inclusion criteria, were included in our study, and were followed for four consecutive deliveries. Patients were divided into three study groups according to the outcome of their consecutive delivery after the primary CS: VBAC $(n=3622)$, elective CS ( $\mathrm{n}=1910)$, or an urgent CS $(\mathrm{n}=1897)$. Survival analysis models were used to investigate the effect of the urgency of CS and the numbers of pregnancy predating the primary CS on peripartum complications.

Results: Women who failed a trial of labor had a higher rate of uterine rupture than those who had a VBAC. Patients who delivered by CS had a higher rate of endometritis than those giving birth vaginally. The rate of cesarean hysterectomy and transfer to other departments increased significantly at the fourth consecutive surgery $(P=0.02$ and $P=0.003$, respectively). VBAC was associated with a $55 \%$ reduction in the risk of intrapartum complications in comparison to a planned CS (hazard ratio [HR] 0.45; 95\% confidence interval [CI]: 0.22-0.89. A greater maternal parity at the time of primary CS was associated with lower intrapartum and postpartum morbidities (HR 0.44; 95\% CI: 0.24-0.79; HR 0.54; 95\% CI: 0.47-0.62, respectively).

Conclusions: (1) A successful VBAC is associated with a reduction in the intrapartum complications; and (2) maternal morbidity increases substantially from the fourth consecutive cesarean delivery.

Keywords: trial of labor, uterine rupture, hysterectomy, blood transfusion, parity

\section{Introduction}

Cesarean section (CS) is the most common surgery performed in the US and its rate is progressively rising throughout the world. ${ }^{1}$ The major increase in the CS rate in western societies was recorded between the 1970s and early 1980s. A transient decrease in primary $\mathrm{CS}$, along with an increase in vaginal birth after cesarean (VBAC), was observed between 1989 and 1996; ${ }^{2}$ however, since 1996, the total cesarean rate has been annually increasing reaching $27.6 \%$ in $2003^{3}$ and $30.1 \%$ in $2006 .^{4}$

Maternal morbidity associated with a CS is substantially higher than that of a vaginal delivery. ${ }^{5-7}$ Therefore, VBAC had been regarded as an effective method to reduce the rate of recurrent cesarean deliveries. However, recent studies demonstrated higher maternal and fetal complications in patients undergoing a trial of labor after 
CS than in those electively delivered by an elective repeated CS. ${ }^{8-10}$ Indeed, a symptomatic uterine rupture occurred in $0.5 \%-0.7 \%$ of women who underwent a trial of labor $^{11}$ and the rate of hypoxic-ischemic encephalopathy increases among patients who attempt a trial of labor especially in cases of uterine rupture during this process. ${ }^{11-14}$ Because of that, the American College of Obstetrics and Gynecology (ACOG), has recommended that a trial of labor after cesarean delivery is to be done only in hospitals that have facilities for emergency CS. The new guidelines say that hospitals ill-equipped for immediate surgery should help women find care elsewhere and have a plan to manage uterine ruptures. ${ }^{15}$

Thus far, the data regarding maternal complications of deliveries following a CS (either by VBAC or elective repetitive $\mathrm{CS}$ ), has mainly focused on the first birth after the primary CS. In contrast, there is a paucity of information concerning maternal morbidity associated with either repeated VBAC or repeated CS (RCS). The aims of this large population cohort study including women with a prior CS were to: (1) compare the maternal morbidity associated with elective repetitive CSs and repeated VBACs; and (2) compare the maternal morbidity of an elective repetitive CS with that of an emergency CS due to failed trial of labor.

\section{Materials and methods Study population and selection of patients}

This retrospective population-based cohort study included 7429 women with a singleton pregnancy who delivered subsequently to a primary CS at the Soroka University Medical Center, a regional tertiary medical center in Beer Sheva, Israel, where all the births in the region take place. Cases were identified by searching a computerized birth records database. Women included in the study were followed up to a maximum of four consecutive deliveries after their primary $\mathrm{CS}$ in the univariate analyses.

\section{Outcome variables}

Data concerning demographic characteristics, medical and obstetric history, as well as pregnancy, delivery, and perinatal outcome, were obtained from the computerized database. The primary outcomes were the rate of intrapartum and postpartum maternal complications during consecutive trials of labor and the intraoperative and postoperative complications of patients with repetitive CS. The data were analyzed by two methods: (1) the effect of recurrent CSs versus repeated VBACs on intrapartum, operative, and postpartum complications; and (2) the effect of a failure in trial of labor on maternal morbidity.

For patients who attempted a VBAC, intrapartum complications included failure to progress during the first and second stages of labor, placental abruption, uterine rupture, uterine scar dehiscence, instrumental delivery, blood product transfusion, and the need for urgent CS. Postpartum complications included postpartum fever, endometritis, urinary tract infection, anemia, uterine rupture, blood product transfusion, and transfer to other departments (ie, intensive care unit).

For patients who underwent a CS, either elective or urgent, intraoperative complications included infection, trauma to adjacent organs, hysterectomy, blood products transfusion, and transfer to another department after CS. Post-operative complications included: reopening of cesarean scar, disruption of cesarean scar, and wound infection.

\section{Statistical analysis}

Maternal demographic characteristics, peripartum complications, and perinatal outcomes were compared with a two-step analysis. First, we compared the rate of complications between patients who underwent repeated VBAC and those who had RCSs. Subsequently, we compared the rate of complications of elective and urgent $\mathrm{CS}$ in patients with RCS and in those who failed a trial of VBAC. Student's $t$-test was used to compare means for normally distributed variables. Chi-square and Fisher exact tests were used to compare categorical variables. Cox proportional hazard regression was performed to investigate the association between repeated VBAC, maternal parity at primary CS, and urgent versus planned $\mathrm{CS}$, to peripartum and postpartum complications. A $P$ value of $<0.05$ was considered significant. Analysis was done using SAS packages (version 9.1; SAS Institute, Cary, NC).

\section{Results}

During the study period (1988-2005) there were 200,012 deliveries by 76,985 women at our medical center; 16,365 of them had a primary CS, of which 7429 women delivered a singleton infant after the primary $\mathrm{CS}$, met the inclusion criteria, and were included in our study (the indication and perinatal complication leading to the primary CS are presented in Supplementary Table 1). The study population was further divided according to the outcome of the subsequent 
delivery after the primary CS: $48.8 \%$ (3622/7429) had a successful trial of labor and were included in the VBAC group; $25.5 \%$ (1897/7429) had an urgent CS due to maternal or fetal indication and comprised the urgent CS group; and 25.7\% (1910/7429) who had an elective CS and were included in that group.

The rate of trial of labor after a primary CS was $74.3 \%$ (5519/7429); of these 65.6\% (3622/5516) succeeded and had a VBAC. The distribution of repeated VBACs, elective and urgent cesarean deliveries up to four consecutive deliveries after the primary CS, are presented in Figure 1A-C. The proportion of VBAC out of all the deliveries increases with each additional consecutive birth, and women in the VBAC group had a higher chance of having four consecutive deliveries after the primary CS than women in the urgent CS (odds ratio [OR], 2.13; 95\%; confidence interval [CI]: 2.43-3.54) or the elective CS (OR, 13; 95\% CI: 9.16-18.55) groups. Of interest is the finding that women included in the urgent CS group had a higher chance of having four consecutive deliveries after the primary CS than those included in the elective CS group (OR, 4.44; 95\% CI: 3.03-6.53) (Figure 2). Demographic characteristics of the study groups are presented in Table 1.

The rate of pregnancy and peripartum complications of the consecutive deliveries after the primary CS is presented in Supplementary Table 2. Patients with RCS, compared to those who had repeated VBACs, had a higher rate of pregnancy complications. A leading indication for repeated urgent CS after the primary CS was labor dystocia; this was the indication for $39.3 \%$ of the urgent CSs in the delivery following the primary CS. Of interest, the rate of labor dystocia declined to about $15 \%$ of the subsequent deliveries (Supplementary Tables 3-5).

Patients with RCS were more likely to require blood products transfusion than patients in the VBAC group. There was no difference in the rate of uterine rupture between those with RCS and those with consecutive VBACs. The rate of these complications did not differ between urgent and elective CS (Table 2). In the first three subsequent deliveries after the primary CS, patients with RCS had higher rates of postpartum fever and endometritis than those with consecutive VBACs (Table 3).

In patients undergoing repeated cesarean deliveries, the rate of blood products transfusion, trauma to adjacent organs, endometritis, postpartum fever, and urinary tract infections did not significantly change with the increase in the number of recurrent cesarean deliveries. However, the rate of cesarean hysterectomy and transfer to other departments increased significantly at the fourth consecutive surgery $(P=0.02$ and $P=0.003$, respectively) (Figure 3 ). The major indications for cesarean hysterectomy were uterine rupture and hemorrhage. The rate of placenta accrete differed among the study group and was highest among the elective CS group $0.73 \%$ (14/1910), followed by the urgent CS group $0.16 \%$ (3/1897), and lowest among those who had VBAC $0.08 \%(3 / 3622$; $P<0.001)$.

The neonatal outcome of the study groups is presented in Supplementary Tables 6-8. The rate of 1-minute Apgar score $<5$ was higher among patients with recurrent $\mathrm{CS}$ than in those with consecutive VBACs in all subsequent pregnancies following the primary CS. However, the rate of 5-minute Apgar score $<7$ did not differ significantly between the study groups in all the subsequent deliveries after the primary CS. The total perinatal mortality rate was higher among women who had a VBAC in the first delivery after the primary CS than in those with recurrent CS, mainly due to a higher rate of antepartum death in the VBAC group. However, in the fourth delivery after the primary CS, women with recurrent CS had a higher rate of total perinatal mortality than those with repeated VBACs, mainly due to a higher rate of postpartum death (Supplementary Tables 7 and 8).

The contribution of a failure in a trial of labor to maternal morbidity is a key question. In order to address it we further analyzed our data including patients who had an urgent cesarean delivery due to labor dystocia. In comparison to women undergoing a nonurgent $\mathrm{CS}$, those who failed a trial of labor had a higher rate of CS complications in general $(P<0.001)$, infections, and the need to transfer to another department in the second and third delivery after the primary CS (Table 4).

In comparison to those who had a successful VBAC, those who failed in a trial of labor had a higher rate of uterine rupture $(P<0.001)$. Of interest, the rate of uterine rupture did not differ between those who had a nonurgent CS and those who failed a trial of labor (Table 5).

To study the additive effect of RCS versus subsequent VBACs we constructed a Cox proportional hazard model separately for intrapartum and postpartum maternal morbidity, in which the outcome of nonurgent repeated morning CS served as the reference point and was compared to the outcome of VBAC and urgent CS at each consecutive delivery. The number of deliveries after the primary CS served as the time parameter. In the model for intrapartum complications, a protective effect was given by any additional VBAC (HR, 
A

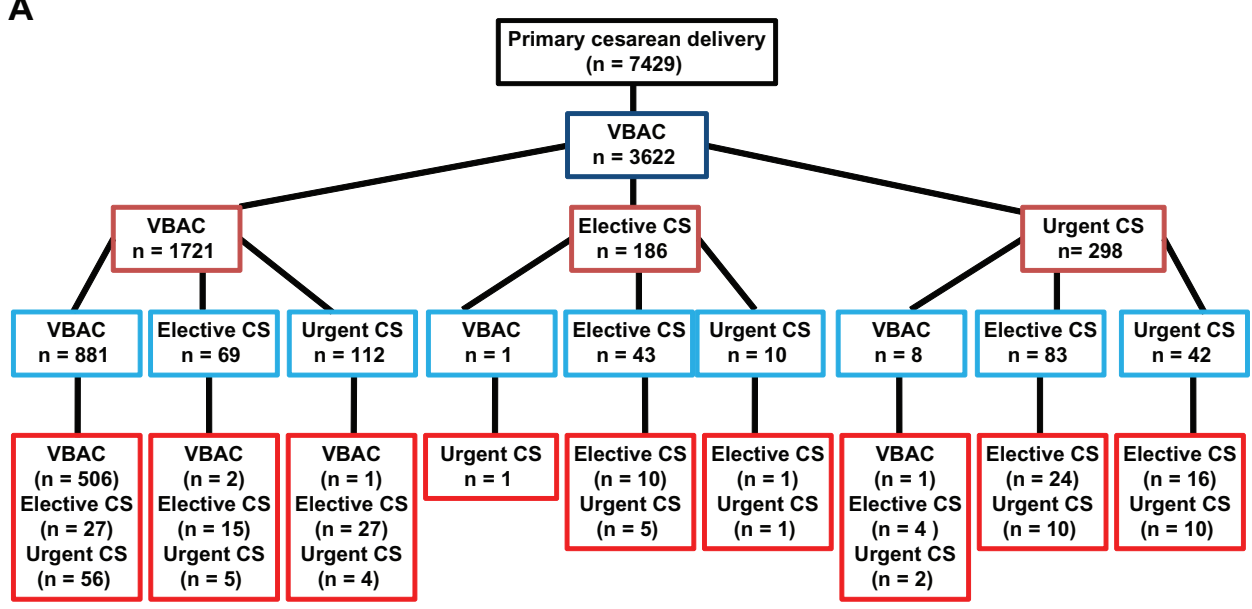

1st delivery after primary CS 2nd delivery after primary CS

3rd delivery after primary CS

4 th delivery after primary CS

B

Primary cesarean delivery
$(\mathrm{n}=7429)$

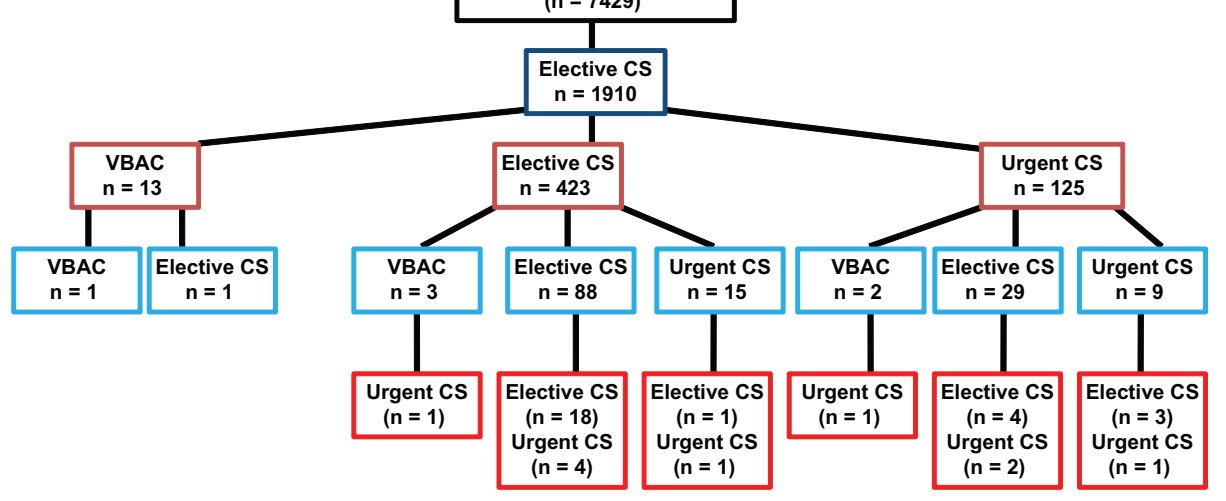

1st delivery after primary CS 2nd delivery after primary CS

3rd delivery after primary CS 4th delivery after primary CS

C

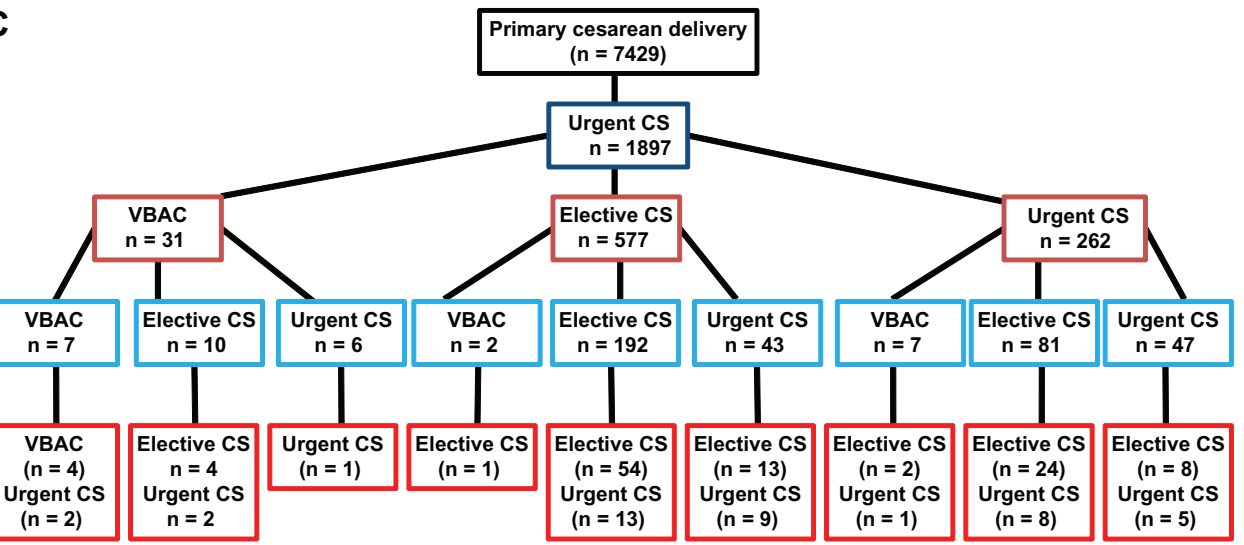

1st delivery after primary CS 2nd delivery after primary CS 3rd delivery after primary CS 4th delivery after primary CS

Figure I Mode of delivery in consecutive deliveries after the primary CS of patients who had a (A) VABC, (B) urgent CS, or (C) elective CS. Abbreviations: $C S$, cesarean section; VBAC, vaginal birth after cesarean. 


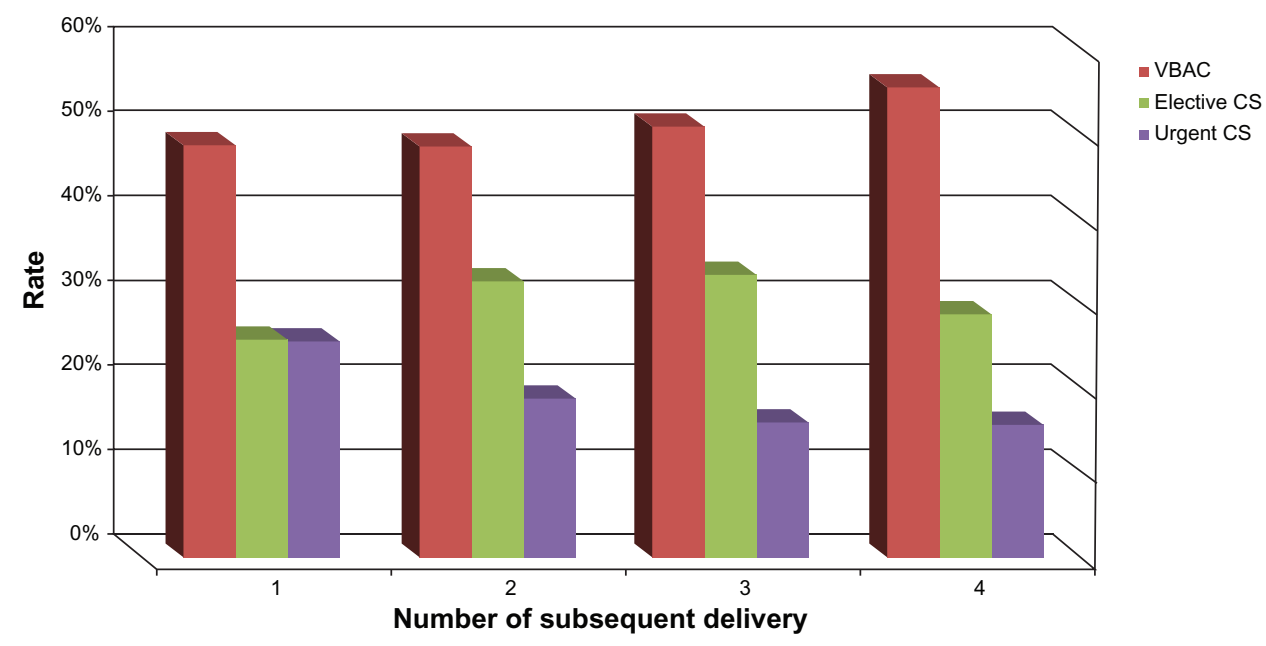

Figure 2 The rate of VBAC, urgent CS and elective CS in the subsequent deliveries after the primary CS. Abbreviations: $C S$, cesarean section; VBAC, vaginal birth after cesarean.

$0.45 ; 95 \% \mathrm{CI}: 0.22-0.9)$ and by maternal parity at primary CS (HR, 0.44; 95\% CI: 0.24-0.79) (Table 6a). Urgent CS was not associated with a significant change in the risk of intrapartum complications versus nonurgent repeated morning CS. In the model for maternal postpartum morbidity, only maternal parity at primary CS had a significant protective effect (HR, 0.54; 95\% CI: 0.47-0.62) (Table 6a). The introduction of maternal age and labor dystocia to the model did not affect its results (Table 6b).

\section{Discussion}

\section{Principal findings of the study}

A successful trial of labor after a primary CS is associated with a higher future parity. In comparison to those who delivered by RCS in all subsequent pregnancies, patients who delivered consecutively by repeated VBACs had a lower maternal morbidity, and a $51.9 \%$ reduction in the risk of intrapartum complications for each successful trial of labor. A failure in a trial of labor is a major cause of maternal morbidity, mainly in the first delivery after the primary CS.

\section{What is the effect of repeated VBACs versus recurrent CS}

The finding that repeated trials of labor ending in successful VBACs are associated with lower maternal morbidity than RCS is novel. This study is the first to compare the outcome of consecutive VBAC to RCSs. Indeed, women who underwent repeated vaginal deliveries after the primary CS had lower rate of blood products transfusion and postpartum infections than women who had repeated cesareans. The finding that each additional VBAC, when compared to elective RCS, was associated with a 55\% reduction in the risk for intrapartumand postpartum complication in comparison to elective CS, is novel and further emphasizes the safety and the benefit of a successful trial of labor.

Repeated VBACs were associated with an overall reduction in intrapartum and postpartum maternal morbidity with

Table I Demographic characteristics of patients at subsequent pregnancy after primary cesarean delivery according to the route of delivery

\begin{tabular}{|c|c|c|c|c|}
\hline Measure & $\operatorname{VBAC}(n=3622)$ & Elective CS $(n=1910)$ & Urgent CS ( I 897) & $P$-value \\
\hline Jewish origin & $43.4 \%(1572 / 3622)$ & $70.6 \%(1348 / 1910)$ & $48.2 \%(9 \mid 4 / 1897)$ & $<0.001$ \\
\hline \multicolumn{5}{|l|}{ Age (years) } \\
\hline Mean \pm SD (n) & $28.15 \pm 5.42(3621)$ & $31.34 \pm 5.21(1906)$ & $29.70 \pm 5.56(1895)$ & $<0.001$ \\
\hline \multicolumn{5}{|l|}{ Gravidity } \\
\hline $2-5$ & $76.4 \%(2764 / 3616)$ & $74.1 \%(1416 / 1910)$ & $74.5 \%(1413 / 1896)$ & 0.1046 \\
\hline $6+$ & $23.6 \%(852 / 3616)$ & $25.9 \%(494 / 1910)$ & $25.5 \%(483 / 1896)$ & \\
\hline \multicolumn{5}{|l|}{ Parity } \\
\hline $2-5$ & $86.4 \%(2928 / 3387)$ & $87.1 \%(1565 / 1796)$ & $85.1 \%(1525 / 1793)$ & 0.1760 \\
\hline $6+$ & $13.6 \%(459 / 3387)$ & $12.9 \%(23|/| 796)$ & I4.9\% (268/I 793) & \\
\hline Infertility treatments & $6.9 \%(25 \mathrm{I} / 3622)$ & $7.5 \%(143 / 1910)$ & $7.2 \%(136 / 1897)$ & 0.7444 \\
\hline
\end{tabular}

Note: Data is presented in percentage (number).

Abbreviations: VBAC, vaginal birth after cesarean; CS, cesarean section. 
every additional delivery. This is in accord with the findings of Mercer et al, ${ }^{16}$ who reported that among 13,532 women from 19 medical centers across the US, VBAC success increased with increasing number of prior VBACs. The rate of uterine rupture decreased after the first successful VBAC and did not increase thereafter. The risk of uterine dehiscence and other peripartum complications also declined substantially after the first successful VBAC. In comparison to the findings of this group, we had a lower rate of uterine rupture in every additional VBAC, and a somewhat lower rate of successful VBAC in each consecutive delivery. The main explanation for this observation is that some of the centers included in the study of Mercer et a ${ }^{16}$ allowed patients with more than one CS to go into a trial of labor, while in our center more than one CS is a contraindication for a trial of labor. Collectively, our findings and those of others support the protective and positive effect of recurrent VBAC on maternal morbidity.

In contrast to the beneficial effect of recurrent VBAC, repeated cesarean deliveries are associated with increased maternal morbidity. We report herein that the rate of uterine rupture, hysterectomy, blood and blood product transfusion, and the need for transferring the patient to other departments rises with the increasing number of cesarean deliveries, especially after the fourth consecutive CS. This is in accord with previous reports: Makoha et al ${ }^{17}$ noted similar elevation maternal morbidity, including placenta previa, placenta accreta, hysterectomy, adhesions, bladder injury, postoperative hemoglobin deficit, and need for blood transfusion with an increasing number of cesarean deliveries; and Silver et $\mathrm{al},{ }^{18}$ for the National Institute of Child Health and Human Development Maternal-Fetal Medicine Units Network, reported that the risks of placenta accreta, cystotomy, bowel injury, ureteral injury, and ileus, the need for postoperative ventilation, intensive care unit admission, hysterectomy, and blood transfusion requiring four or more units, and the duration of operative time and hospital stay, significantly increased with an increasing number of cesarean deliveries. Similarly to our findings, Silver et a ${ }^{18}$ reported that there was a substantial increase in the risk for several morbidities, including placenta accreta, cystotomy, and need for hysterectomy or intensive care unit admission with the fourth or greater cesarean delivery. Thus, although there is no strict cut off regarding the number of consecutive CSs, it seems that the maternal risk for serious intraoperative complications increases substantially from the fourth RCS. This information should 


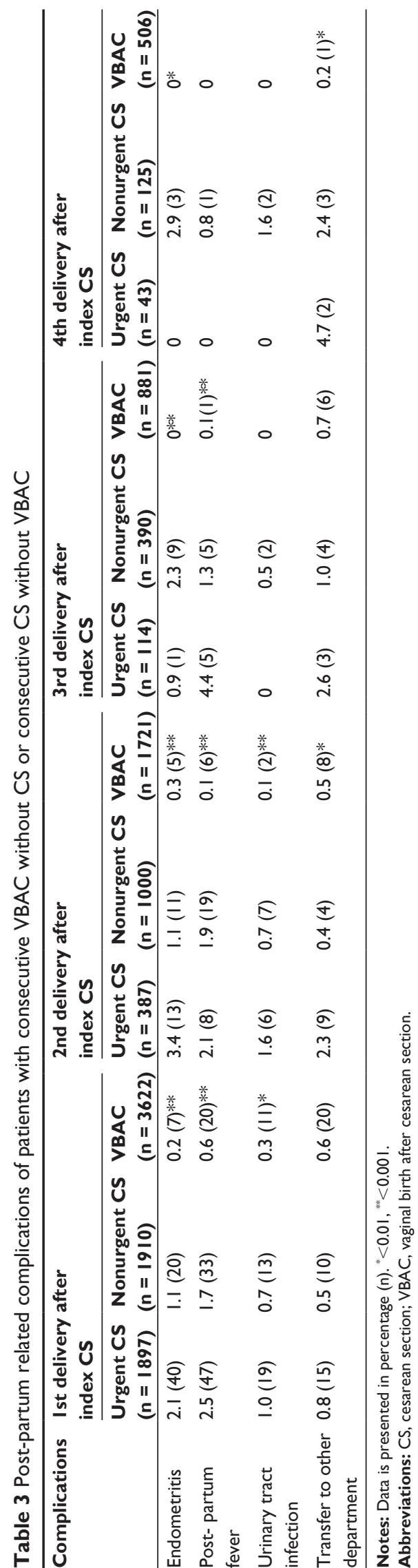

be included while counseling patients regarding repeated cesarean births.

An additional effect of repeated VBACs is the higher number of subsequent deliveries after the primary CS in comparison to those of women who had an elective or urgent RCS. Of interest is the fact that a higher proportion of those who underwent an urgent CS, immediately after the primary CS, had four subsequent pregnancies in comparison to those who had an elective CS. This finding is novel, and it may reflect the differences in the study population; meaning that a higher proportion of patients who choose to have an elective cesarean after the primary CS have a tendency to smaller families than those who attempt a trial of labor after the primary CS. Indeed, the sharp decline in the number of deliveries in this group is after the third cesarean. Guise et a $\mathrm{l}^{19}$ proposed that a woman's decision to undergo a trial of labor after a primary CS is a complex process that is affected by medical, cultural, behavioral, and legal factors. The retrospective nature of our study does not allow us a deeper and more thorough investigation into these factors in relation to our population. A specially designed prospective study will need to be conducted in order to address the effect of these factors on the patient's decision to undergo a trial of labor versus elective CS; nevertheless, educating women about their options early enough in pregnancy for them to make an informed choice is a key factor in this process.

\section{What is the effect of labor dystocia on the success of a trial of labor?}

The success of a trial of labor is an end point of many variables. Some of these parameters have been included in different prediction models ${ }^{20-23}$ aiming to assess the probability of a given patient to deliver vaginally after a primary CS. According to our findings, labor dystocia is a significant contributor to a failure of a trial of labor mainly in the first delivery after a primary CS. Dystocia was the indication for almost $40 \%$ of the urgent CS in the delivery following the primary CS, yet in the subsequent deliveries, its rate declined to about $15 \%$ of the urgent CS. This finding further emphasizes previously published data that women with a history of a labor dystocia which led to their primary CS have a lower chance to succeed in a trial of labor in the subsequent birth. ${ }^{24-27}$ In addition, our finding that the rate of dystocia as an indication for urgent CS declines in the following deliveries suggests that women who twice failed a trial of labor probably deliver by elective CS in 


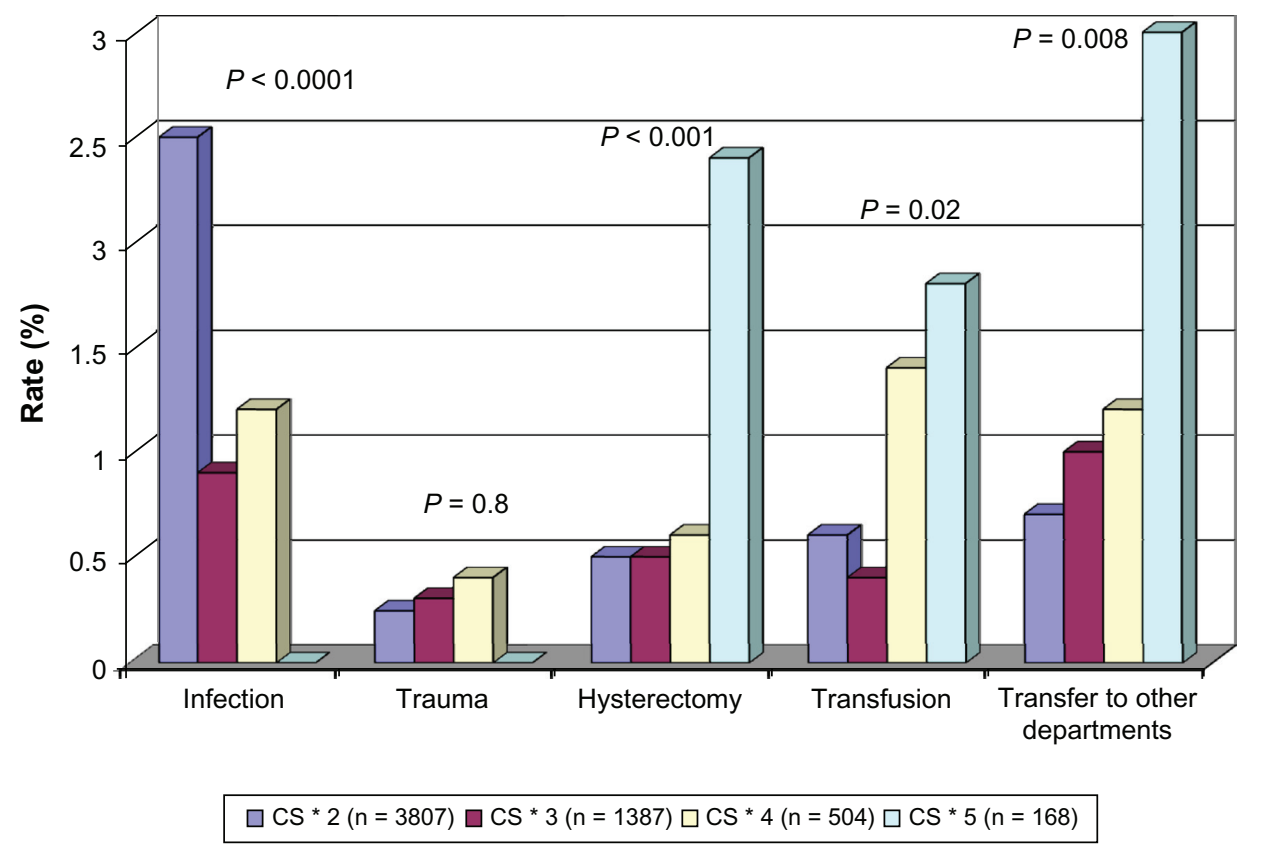

Figure 3 Intraoperative complications of patients with recurrent CS

Abbreviation: CS, cesarean section.

their subsequent pregnancies or stop delivering. Indeed, in our cohort, only $45.9 \%$ of women who had an urgent CS during the subsequent birth after the primary cesarean had additional deliveries, mostly by elective CS. In contrast to this group, $60.9 \%$ of women who had a successful VBAC after the primary CS continued to deliver and only $8.4 \%$ of them had an elective CS. Collectively the data presented herein suggest that the success in vaginal delivery at the subsequent birth after the primary CS has important implication for maternals health and reproductive future. Those who prevail in the trial of labor and have a VBAC will have overall higher pregnancy rate and lower maternal morbidity than those who failed a trial of labor and women who chooses elective RCS.

\section{Strength and limitation of the study}

The limitation of this study is its retrospective nature and the fact that the data are derived from a database which has inherited limitations. Moreover, in the analysis of the data it seems that the inclination of the medical team is to go for a RCS whenever the patient has an additional pregnancy complication aside from the previous CS, which may lead to a bias towards allowing a trial of labor only for the healthier women. We could not ascertain this bias; nevertheless, the large number of deliveries included in our study over such a long period, as well as the fact that all the deliveries of our region take place at our medical center, assure us that the data presented herein is a representative sample of our obstetric population.

Table 4 Intraoperative complications of patients who failed a trial of labor and those who had a nonurgent CS

\begin{tabular}{|c|c|c|c|c|c|c|}
\hline \multirow[t]{2}{*}{ Complications } & \multicolumn{3}{|c|}{ 2nd delivery after index CS } & \multicolumn{3}{|c|}{ 3rd delivery after index CS } \\
\hline & $\begin{array}{l}\text { Failed TOL } \\
(n=105)\end{array}$ & $\begin{array}{l}\text { Nonurgent CS } \\
(\mathrm{n}=1 \mid \mathrm{I} 6)\end{array}$ & $P$-value & $\begin{array}{l}\text { Failed TOL } \\
(n=46)\end{array}$ & $\begin{array}{l}\text { Nonurgent CS } \\
(\mathrm{n}=596)\end{array}$ & $P$-value \\
\hline Any CS complications & $3.8(4)$ & $\mathrm{I} .8(2 \mathrm{I})$ & 0.139 & $6.5(3)$ & $2.4(14)$ & 0.115 \\
\hline Infection & $1.9(2)$ & $0.7(8)$ & 0.192 & $2.2(1)$ & $0.8(5)$ & 0.361 \\
\hline Trauma to adjacent organs & 0 & $0.3(3)$ & 1.000 & $2.2(1)$ & $0.3(2)$ & 0.200 \\
\hline Hysterectomy & $\mathrm{I} .0(\mathrm{l})$ & $0.5(6)$ & 0.449 & $4.4(2)$ & $0.7(4)$ & 0.063 \\
\hline Blood products transfusion & $\mathrm{I} .0(\mathrm{I})$ & $0.3(4)$ & 0.346 & $2.2(1)$ & $0.7(4)$ & 0.311 \\
\hline Transfer to other department & 0 & $0.5(6)$ & 1.000 & $2.2(\mathrm{I})$ & $0.5(3)$ & 0.258 \\
\hline
\end{tabular}

Notes: Data is presented in percentage (n). Failed TOL was defined as not-planned CS with labor dystocia. Nonurgent CS was defined as CS without indication for urgent CS when section is performed between 8am-3pm.

Abbreviations: CS, cesarean section; TOL, trial of labor. 
Table 5 Delivery-related complications of patients who failed a trial of labor, those who had a nonurgent CS and those who had a VBAC

\begin{tabular}{|c|c|c|c|c|c|c|c|c|}
\hline \multirow[t]{2}{*}{ Complications } & \multicolumn{4}{|c|}{ 2nd delivery after index CS } & \multicolumn{4}{|c|}{ 3rd delivery after index CS } \\
\hline & $\begin{array}{l}\text { Failed TOL } \\
(n=105)\end{array}$ & $\begin{array}{l}\text { Nonurgent CS } \\
(n=1186)\end{array}$ & $\begin{array}{l}\text { VBAC } \\
(n=1765)\end{array}$ & $P$-value & $\begin{array}{l}\text { Failed TOL } \\
(n=46)\end{array}$ & $\begin{array}{l}\text { Nonurgent CS } \\
(n=596)\end{array}$ & $\begin{array}{l}\text { VBAC } \\
(n=9 \mid 2)\end{array}$ & $P$-value \\
\hline $\begin{array}{l}\text { Any delivery } \\
\text { complications }\end{array}$ & $4.8(5)$ & $3.6(43)$ & $0.1(I)$ & $<0.001$ & $2.2(I)$ & $4.2(25)$ & $0.2(2)$ & $<0.001$ \\
\hline Dehiscence & $1.9(2)$ & $3.2(38)$ & 0 & $<0.00$ I & 0 & $3.4(20)$ & $0.2(2)$ & $<0.001$ \\
\hline $\begin{array}{l}\text { Blood products } \\
\text { transfusion }\end{array}$ & $1.0(\mathrm{I})$ & $0.3(4)$ & 0 & 0.010 & $2.2(\mathrm{I})$ & $0.7(4)$ & 0 & 0.008 \\
\hline Uterine rupture & $2.9(3)$ & $0.2(2)$ & $0.1(I)$ & $<0.001$ & $2.2(1)$ & $0.3(2)$ & 0 & 0.016 \\
\hline
\end{tabular}

Notes: Data is presented in percentage. Failed TOL was defined as not-planned CS with labor dystocia; Nonurgent CS was defined as CS without indication for urgent CS when section is performed between 8am-3pm.

Abbreviations: CS, cesarean section; TOL, trial of labor.

\section{Conclusion}

In summary, repeated VBACS are associated with a lower intrapartum maternal morbidity than planned recurrent cesarean deliveries. The recently published National Institute of Child Health and Human Development (Bethesda, MD) consensus regarding VBAC, states that about $30 \%$ of maternal fetal medicine fellows do not consult patients with a previous CS regarding the possibility of a trial of labor. ${ }^{2}$ The findings of the current study and others may be used to reduce this trend among obstetricians and increase the rate of trial of labor. Moreover, the findings of this study further emphasize the point that a woman who desires large families should be offered a trial of labor after her primary cesarean delivery, especially if she had vaginal deliveries prior to her CS.

\section{Supplementary clinical definitions}

Parity groups were defined as follows: multipara (two to five deliveries) and grand-multipara (six or more deliveries). Hypertension was defined in the presence of blood pressure $\geq 140 / 90 \mathrm{mmHg}$ recorded in two separate measurements at least 4 hours apart. Mild hypertension was defined as a diastolic blood pressure $\geq 90 \mathrm{mmHg}$ and $<110 \mathrm{mmHg}$ and/or systolic blood pressure $\geq 140 \mathrm{mmHg}$ and $<160 \mathrm{mmHg}$. Severe hypertension was defined in the presence of diastolic blood pressure $\geq 110 \mathrm{mmHg}$ and systolic blood pressure $\geq 160 \mathrm{mmHg}$. Gestational hypertension was defined in the presence of hypertension developed after 20 weeks of gestation without proteinuria. Preeclampsia was diagnosed in the presence of elevated blood pressure and proteinuria of at least +1 in dipstick; its severity was defined according to the severity of hypertension and/or one of the following +3 proteinuria by dipstick, thrombocytopenia $\leq 100,000$, elevated liver enzymes, persistent headache and/or blurred vision. ${ }^{28}$ Gestational diabetes was diagnosed according to oral glucose tolerance test and was classified according to White's classification. ${ }^{29}$ Hydramnios (amniotic fluid index [AFI]) $>25 \mathrm{~cm}$ or when a vertical pocket of at least $8 \mathrm{~cm}$ was measured or as a subjective estimation of increased amniotic fluid volume. Oligohydramnios (AFI) $<5 \mathrm{~cm}$, a real-time scanner equipped with a $3.5 / 5 \mathrm{MHz}$ transducer of appropriate focal length estimated amniotic fluid volume. Preterm delivery was defined as delivery before completion of 37 weeks of gestation.

Newborns were classified according to their weight as: small for gestational age (SGA), birthweight less than the 10th percentile; adequate for gestational age (AGA), birthweight from 10th-90th percentile; and large for gestational age (LGA), birthweight $>90$ th percentile according to regional growth curves. ${ }^{30}$ Prelabor rupture of membranes

Table 6a Cox proportional hazard ratio for factors associated with intra-partum and post-partum complications

\begin{tabular}{|c|c|c|c|c|c|c|}
\hline \multirow[t]{3}{*}{ Variable } & \multicolumn{3}{|c|}{ Intra-partum complications } & \multicolumn{3}{|c|}{ Post-partum complications } \\
\hline & Parameter & Hazard & 95\% Confidence & Parameter & Hazard & 95\% Confidence \\
\hline & Estimate & Ratio & interval & Estimate & Ratio & interval \\
\hline VBAC & -0.807 & 0.45 & $0.22 ; 0.90$ & -0.044 & 0.96 & $0.78 ; 1.18$ \\
\hline Unplanned cesarean delivery & -0.110 & 0.90 & $0.44 ; 1.83$ & 0.117 & 1.12 & $0.88 ; 1.43$ \\
\hline First CS & 0.829 & 0.44 & $0.24 ; 0.79$ & -0.622 & 0.54 & $0.47 ; 0.62$ \\
\hline
\end{tabular}

Note: VBAC and unplanned cesarean delivery are compared to planned cesarean delivery.

Abbreviations: First CS, the pregnancy number in which the patient undergoes cesarean delivery; CS, cesarean section; VBAC, vaginal birth after cesarean section. 
Table 6b Cox proportional hazard ratio for factors associated with intra-partum and post-partum complications

\begin{tabular}{|c|c|c|c|c|c|c|}
\hline \multirow[t]{2}{*}{ Variable } & \multicolumn{3}{|c|}{ Intra-partum complications } & \multicolumn{3}{|c|}{ Post-partum complications } \\
\hline & $\begin{array}{l}\text { Parameter } \\
\text { Estimate }\end{array}$ & $\begin{array}{l}\text { Hazard } \\
\text { Ratio }\end{array}$ & $\begin{array}{l}95 \% \\
\text { Confidence } \\
\text { interval }\end{array}$ & $\begin{array}{l}\text { Parameter } \\
\text { Estimate }\end{array}$ & $\begin{array}{l}\text { Hazard } \\
\text { Ratio }\end{array}$ & $\begin{array}{l}\text { 95\% Confidence } \\
\text { interval }\end{array}$ \\
\hline VBAC & -0.85 & 0.43 & $0.21 ; 0.86$ & -0.07 & 0.93 & $0.75 ;$ I.I5 \\
\hline $\begin{array}{l}\text { Unplanned cesarean } \\
\text { delivery }\end{array}$ & 0.02 & 1.02 & $0.48 ; 2.17$ & 0.07 & 1.07 & $0.82 ; 1.40$ \\
\hline First CS & -0.77 & 0.46 & $0.25 ; 0.83$ & -0.60 & 0.55 & $0.48 ; 0.63$ \\
\hline Labor dystocia & -0.63 & 0.33 & $0.15 ; 1.89$ & -0.11 & I.II & $0.81 ; 1.54$ \\
\hline Maternal age & -0.05 & 0.95 & $0.89 ; 1.01$ & -0.02 & 0.98 & $0.96 ; 0.996$ \\
\hline
\end{tabular}

Note: VBAC and unplanned cesarean delivery are compared to planned cesarean delivery

Abbreviations: CS, cesarean section; VBAC, vaginal birth after cesarean section; First CS, the pregnancy number in which the patient undergoes cesarean delivery.

(PROM) was defined as rupture of the chorioamniotic membranes before the onset of labor. Uterine rupture was defined as a complete tear of the uterine wall, including the visceral peritoneum with establishment of a direct communication between the uterine and abdominal cavities. Dehiscence was defined as an opening of the previous cesarean scar with intact visceral peritoneum and no direct communication between the uterine and abdominal cavities. Postpartum fever was defined as maternal temperature $\geq 38^{\circ} \mathrm{C}$, which developed at least 24 hours after delivery recorded in two different measurements at least 4 hours apart or one measurement of maternal temperature of $\geq 38.5^{\circ} \mathrm{C}$ regardless of the time after delivery. Endometritis was defined as postpartum maternal fever with clinical signs of tenderness above the uterine fundus or during cervical manipulation, foul vaginal discharge and positive endometrial culture. Wound infection was defined according to either clinical signs of infection or positive wound culture. Wound dehiscence was defined as spontaneous opening of CS wound including the abdominal fascia.

\section{Disclosure}

The authors report no conflicts of interest in this work and the study was self-funded.

\section{References}

1. Martin JA, Hamilton BE, Sutton PD, Ventura SJ, Menacker F, Kirmeyer S. Births: final data for 2004. Natl Vital Stat Rep. 2006;55(1):1-101.

2. Bangdiwala SI, Brown SS, Cunningham FG, et al. NIH Consensus Development Conference Draft Statement on Vaginal Birth After Cesarean: New Insights. NIH Consens State Sci Statements. 2010 Mar 10;27(3). [Epub ahead of print.]

3. Menacker F. Trends in cesarean rates for first births and repeat cesarean rates for low-risk women: United States, 1990-2003. Natl Vital Stat Rep. 2005;54(4):1-8.

4. Martin JA, Hamilton BE, Sutton PD, et al; Centers for Disease Control and Prevention National Center for Health Statistics National Vital Statistics System. Births: final data for 2005. Natl Vital Stat Rep. 2007;56(6):1-103.
5. Lydon-Rochelle MT, Gardella C, Cárdenas V, Easterling TR. Repeat cesarean delivery: what indications are recorded in the medical chart? Birth. 2006;33(1):4-11.

6. Allen VM, OConnell CM, Baskett TF. Maternal morbidity associated with cesarean delivery without labor compared with induction of labor at term. Obstet Gynecol. 2006;108(2):286-294.

7. Miller DA, Chollet JA, Goodwin TM. Clinical risk factors for placenta previa-placenta accreta. Am J Obstet Gynecol. 1997;177(1):210-214.

8. Flamm BL, Goings JR, Liu Y, Wolde-Tsadik G. Elective repeat cesarean delivery versus trial of labor: a prospective multicenter study. Obstet Gynecol. 1994;83(6):927-932.

9. Grobman WA, Gilbert S, Landon MB, et al. Outcomes of induction of labor after one prior cesarean. Obstet Gynecol. 2007;109(2 Pt 1):262-269.

10. McMahon MJ, Luther ER, Bowes WA Jr, Olshan AF. Comparison of a trial of labor with an elective second cesarean section. $N$ Engl J Med. 1996;335(10):689-695.

11. Landon MB, Hauth JC, Leveno KJ, et al; National Institute of Child Health and Human Development Maternal-Fetal Medicine Units Network. Maternal and perinatal outcomes associated with a trial of labor after prior cesarean delivery. $N$ Engl J Med. 2004;351(25):2581-2589.

12. Endres LK, Barnhart K. Spontaneous second trimester uterine rupture after classical cesarean. Obstet Gynecol. 2000;96(5 Pt 2):806-808.

13. Guise JM, McDonagh MS, Osterweil P, Nygren P, Chan BK, Helfand M. Systematic review of the incidence and consequences of uterine rupture in women with previous caesarean section. $B M J$. 2004;329(7456):19-25.

14. Wen SW, Rusen ID, Walker M, et al; Maternal Health Study Group, Canadian Perinatal Surveillance System. Comparison of maternal mortality and morbidity between trial of labor and elective cesarean section among women with previous cesarean delivery. Am J Obstet Gynecol. 2004;191(4):1263-1269.

15. ACOG Practice bulletin no. 115: vaginal birth after previous cesarean delivery. Obstet Gynecol. 2010;116(2 Pt 1):450-463.

16. Mercer BM, Gilbert S, Landon MB, et al; National Institute of Child Health and Human Development Maternal-Fetal Medicine Units Network. Labor outcomes with increasing number of prior vaginal births after cesarean delivery. Obstet Gynecol. 2008;111(2 Pt 1):285-291.

17. Makoha FW, Felimban HM, Fathuddien MA, Roomi F, Ghabra T. Multiple cesarean section morbidity. Int J Gynaecol Obstet. 2004;87(3): 227-232.

18. Silver RM, Landon MB, Rouse DJ, et al; National Institute of Child Health and Human Development Maternal-Fetal Medicine Units Network. Maternal morbidity associated with multiple repeat cesarean deliveries. Obstet Gynecol. 2006;107(6):1226-1232.

19. Guise JM, Eden K, Emeis C, et al. Vaginal birth after cesarean: new insights. Evid Rep Technol Assess (Full Rep). 2010:1-397.

20. Costantine MM, Fox K, Byers BD, et al. Validation of the prediction model for success of vaginal birth after cesarean delivery. Obstet Gynecol. 2009;114(5):1029-1033. 
21. Grobman WA, Lai Y, Landon MB, et al; National Institute of Child Health and Human Development (NICHD) Maternal-Fetal Medicine Units Network (MFMU). Development of a nomogram for prediction of vaginal birth after cesarean delivery. Obstet Gynecol. 2007;109(4):806-812.

22. Grobman WA, Lai Y, Landon MB, et al. Does information available at admission for delivery improve prediction of vaginal birth after cesarean? Am J Perinatol. 2009;26(10):693-701.

23. Grobman WA, Lai Y, Landon MB, et al; Eunice Kennedy Shriver National Institute of Child Health and Human Development MaternalFetal Medicine Units Network. Can a prediction model for vaginal birth after cesarean also predict the probability of morbidity related to a trial of labor? Am J Obstet Gynecol. 2009;200(1):56. e1-e6.

24. Peaceman AM, Gersnoviez R, Landon MB, et al; National Institute of Child Health and Human Development Maternal-Fetal Medicine Units Network. The MFMU Cesarean Registry: impact of fetal size on trial of labor success for patients with previous cesarean for dystocia. Am J Obstet Gynecol. 2006;195(4):1127-1131.
25. Landon MB, Leindecker S, Spong CY, et al; National Institute of Child Health and Human Development Maternal-Fetal Medicine Units Network. The MFMU Cesarean Registry: factors affecting the success of trial of labor after previous cesarean delivery. Am J Obstet Gynecol. 2005;193(3 Pt 2):1016-1023.

26. Bujold E, Gauthier RJ. Should we allow a trial of labor after a previous cesarean for dystocia in the second stage of labor? Obstet Gynecol. 2001;98(4):652-655.

27. Bais JM, van der Borden DM, Pel M, et al. Vaginal birth after caesarean section in a population with a low overall caesarean section rate. Eur J Obstet Gynecol Reprod Biol. 2001;96(2):158-162.

28. ACOG Committee on Practice Bulletins-Obstetrics. ACOG practice bulletin. Diagnosis and management of preeclampsia and eclampsia. Number 33, Jan 2002. Obstet Gynecol. 2002;99(1):159-167.

29. White P. Pregnancy complicating diabetes. Am J Med. 1949;7(5): 609-616.

30. Leiberman JR, Fraser D, Weitzman S, Glezerman M. Birthweight curves in southern Israel populations. Isr J Med Sci. 1993;29(4):198-203. 


\section{Supplementary Table}

Table SI Indications and perinatal complications for primary CS

\begin{tabular}{ll}
\hline Measure & Rate \\
\hline Preeclampsia & $10.8 \%(802 / 7429)$ \\
GDM class A & $6.4 \%(474 / 7429)$ \\
GDM class B-R & $2.3 \%(169 / 7429)$ \\
Hydramnios & $7.2 \%(536 / 7429)$ \\
Olihydramnios & $6.0 \%(536 / 7429)$ \\
PROM & $9.3 \%(689 / 3622)$ \\
Mal presentation & $33.2 \%(2467 / 7429)$ \\
Preterm delivery & $17.5 \%(1299 / 7429)$ \\
PPROM & $2.5 \%(183 / 7429)$ \\
Arrest of Ist stage of labor & $18.8 \%(1393 / 7429)$ \\
Arrest of 2nd stage of labor & $5.6 \%(415 / 7429)$ \\
NRFHR & $21.2 \%(157 / / 7429)$ \\
Prolapse of cord & $3.6 \%(269 / 7429)$ \\
Placenta previa & $3.1 \%(229 / 7429)$ \\
Uterine rupture & $0.2 \%(12 / 7429)$ \\
\hline
\end{tabular}

Abbreviations: GDM, gestational diabetes; PROM, prelabor rupture of membranes; PPROM, preterm prelabor rupture of membranes; NRFHR, non reassuring fetal heart rate.

Table S2 Peri-partum complications in the first delivery after primary CS

\begin{tabular}{|c|c|c|c|c|}
\hline Measure & $\begin{array}{l}\text { VBAC } \\
(N=3622)\end{array}$ & $\begin{array}{l}\text { Elective CS } \\
(N=1910)\end{array}$ & $\begin{array}{l}\text { Urgent CS } \\
(N=1897)\end{array}$ & $P$-value \\
\hline Mild PET & $3.0 \%(108 / 3622)$ & $3.7 \%(70 / 1910)$ & $5.2 \%(98 / 1897)$ & 0.0002 \\
\hline Severe PET & $0.8 \%(28 / 3622)$ & $0.0 \%(0 / 1910)$ & $5.6 \%(107 / 1897)$ & $<0.000$ I \\
\hline Chronic hypertension & $1.8 \%(66 / 3622)$ & $4.5 \%(86 / 1910)$ & $5.2 \%(99 / 1897)$ & $<0.0001$ \\
\hline GDM class $A$ & $4.9 \%(179 / 3622)$ & $10.4 \%(198 / 1910)$ & $8.9 \%(168 / 1897)$ & $<0.0001$ \\
\hline GDM class B-R & $1.3 \%(46 / 3622)$ & $4.8 \%(92 / 1910)$ & $4.0 \%(75 / 1897)$ & $<0.0001$ \\
\hline Hydramnios & $3.7 \%(135 / 3622)$ & $8.8 \%(168 / 1910)$ & $8.9 \%(169 / 1897)$ & $<0.0001$ \\
\hline Olihydramnios & $2.3 \%(83 / 3622)$ & $3.0 \%(58 / 1910)$ & $4.2 \%(80 / 1897)$ & 0.0003 \\
\hline PROM & $7.2 \%(262 / 3622)$ & $4.5 \%(85 / 1910)$ & $9.8 \%(186 / 1897)$ & $<0.0001$ \\
\hline Mal presentation & $1.4 \%(49 / 3622)$ & $18.1 \%(345 / 1910)$ & $12.4 \%(235 / 1897)$ & $<0.0001$ \\
\hline Preterm delivery & $8.3 \%(300 / 3622)$ & $10.1 \%(192 / 1910)$ & $14.1 \%(268 / 1896)$ & $<0.0001$ \\
\hline PPROM & $1.2 \%(45 / 3622)$ & $0.8 \%(16 / 1910)$ & $1.6 \%(30 / 1897)$ & 0.1125 \\
\hline Arrest of Ist stage of labor & $0.4 \%(14 / 3622)$ & $0.0 \%(0 / 1910)$ & $33.2 \%(630 / 1897)$ & $<0.000$ I \\
\hline Arrest of 2 nd stage of labor & $3.6 \%(129 / 3622)$ & $0.0 \%(0 / 1910)$ & $6.1 \%(116 / 1897)$ & $<0.0001$ \\
\hline Arrest of Ist or 2 nd stage of labor & $3.9 \%(143 / 3622)$ & $0.0 \%(0 / 1910)$ & $39.3 \%(746 / 1897)$ & $<0.0001$ \\
\hline NRFHR & $2.2 \%(80 / 3622)$ & $0.0 \%(0 / 1910)$ & $12.1 \%(229 / 1897)$ & $<0.0001$ \\
\hline Prolapse of cord & $0.2 \%(6 / 3622)$ & $0.0 \%(0 / 1910)$ & $2.2 \%(42 / 1897)$ & $<0.0001$ \\
\hline Placenta previa & $0.1 \%(4 / 3622)$ & $2.6 \%(50 / 1910)$ & $1.2 \%(22 / 1897)$ & $<0.0001$ \\
\hline Uterine rupture & $0.1 \%(3 / 3622)$ & $0.3 \%(5 / 1910)$ & $0.3 \%(5 / 1897)$ & 0.1793 \\
\hline
\end{tabular}

Abbreviations: PET, preeclampsia; GDM, gestational diabetes; PROM, prelabor rupture of membranes; PPROM, preterm prelabor rupture of membranes; NRFHR, non reassuring fetal heart rate. 
Table S3 Peri-partum complications in the second delivery after primary CS

\begin{tabular}{|c|c|c|c|c|}
\hline Measure & $\begin{array}{l}\text { VBAC } \\
(N=1765)\end{array}$ & $\begin{array}{l}\text { Elective CS } \\
(N=1 \mid 86)\end{array}$ & $\begin{array}{l}\text { Urgent CS } \\
(N=685)\end{array}$ & $P$-value \\
\hline Mild PET & $2.4 \%(42 / 1765)$ & $1.9 \%(23 / 1186)$ & $2.8 \%(19 / 685)$ & 0.4934 \\
\hline Severe PET & $0.6 \%(10 / 1765)$ & $0.0 \%(0 / 1186)$ & $7.2 \%(49 / 685)$ & $<0.000$ I \\
\hline Chronic hypertension & $1.8 \%(32 / 1765)$ & $4.5 \%(53 / 1 \mid 186)$ & $5.7 \%(39 / 685)$ & $<0.0001$ \\
\hline GDM class $A$ & $4.1 \%(72 / 1765)$ & $8.9 \%(105 / 1186)$ & $9.1 \%(62 / 685)$ & $<0.000$ I \\
\hline GDM class B-R & $\mathrm{I} .2 \%(2 \mathrm{I} / \mathrm{I} 65)$ & $4.0 \%(48 / 1186)$ & $3.6 \%(25 / 685)$ & $<0.000$ I \\
\hline Hydramnios & $3.6 \%(64 / 1765)$ & $8.3 \%(99 / 1186)$ & $7.9 \%(54 / 685)$ & $<0.0001$ \\
\hline Olihydramnios & $2.2 \%(39 / 1765)$ & $2.2 \%(26 / 1186)$ & $3.5 \%(24 / 685)$ & 0.1393 \\
\hline PROM & $6.7 \%(118 / 1765)$ & $1.5 \%(18 / 1186)$ & $9.5 \%(65 / 685)$ & $<0.0001$ \\
\hline Mal presentation & $1.3 \%(23 / 1765)$ & $11.8 \%(140 / 1186)$ & $14.6 \%(100 / 685)$ & $<0.0001$ \\
\hline Preterm delivery & $7.6 \%(135 / 1765)$ & $14.1 \%(167 / 1186)$ & $26.0 \%(178 / 685)$ & $<0.000$ I \\
\hline PPROM & I.I\% (20/1765) & $0.6 \%(7 / 1 / 86)$ & $3.2 \%(22 / 685)$ & $<0.000$ I \\
\hline Arrest of Ist stage of labor & $0.1 \%(2 / 1765)$ & $0.0 \%(0 / 1186)$ & II.5\% (79/685) & $<0.0001$ \\
\hline Arrest of 2 nd stage of labor & I.2\% (2I/I765) & $0.0 \%(0 / 1 / 86)$ & $3.1 \%(21 / 685)$ & $<0.000$ I \\
\hline Arrest of Ist or 2 nd stage of labor & $1.3 \%(23 / 1765)$ & $0.0 \%(0 / 1186)$ & $14.6 \%(100 / 685)$ & $<0.0001$ \\
\hline NRFHR & I.4\% (25/I765) & $0.0 \%(0 / 1 / 86)$ & $8.5 \%(58 / 685)$ & $<0.0001$ \\
\hline Prolapse of cord & $0.2 \%(3 / 1765)$ & $0.0 \%(0 / 1186)$ & $2.2 \%(15 / 685)$ & $<0.0001$ \\
\hline Placenta previa & $0.0 \%(0 / 1765)$ & $2.3 \%(27 / I 186)$ & $1.3 \%(9 / 685)$ & $<0.000$ I \\
\hline Uterine rupture & $0.1 \%(1 / 1765)$ & $0.2 \%(2 / 1186)$ & $0.6 \%(4 / 685)$ & 0.0274 \\
\hline
\end{tabular}

Abbreviations: PET, preeclampsia; GDM, gestational diabetes; PROM, prelabor rupture of membranes; PPROM, preterm prelabor rupture of membranes; NRFHR, non reassuring fetal heart rate.

Table S4 Peri-partum complications in the third delivery after primary CS

\begin{tabular}{|c|c|c|c|c|}
\hline Measure & $\begin{array}{l}\text { VBAC } \\
(N=9 \mid 2)\end{array}$ & $\begin{array}{l}\text { Elective CS } \\
(N=596)\end{array}$ & $\begin{array}{l}\text { Urgent CS } \\
(N=284)\end{array}$ & $P$-value \\
\hline Mild PET & $2.5 \%(23 / 9 \mid 2)$ & $1.7 \%(10 / 596)$ & $1.8 \%(5 / 284)$ & 0.4848 \\
\hline Severe PET & $0.7 \%(6 / 9 \mid 2)$ & $0.0 \%(0 / 596)$ & $9.2 \%(26 / 284)$ & $<0.000$ I \\
\hline Chronic hypertension & $1.3 \%(12 / 912)$ & $4.2 \%(25 / 596)$ & $5.3 \%(15 / 284)$ & 0.0002 \\
\hline GDM class A & $5.3 \%(48 / 9 \mid 2)$ & $9.2 \%(55 / 596)$ & $8.8 \%(25 / 284)$ & 0.0069 \\
\hline GDM class B-R & $1.3 \%(12 / 912)$ & $3.7 \%(22 / 596)$ & $4.2 \%(12 / 284)$ & 0.0027 \\
\hline Hydramnios & $4.4 \%(40 / 9 \mid 2)$ & $7.6 \%(45 / 596)$ & $8.8 \%(25 / 284)$ & 0.0055 \\
\hline Olihydramnios & $2.4 \%(22 / 9 / 2)$ & $2.0 \%(12 / 596)$ & $3.5 \%(10 / 284)$ & 0.3985 \\
\hline PROM & $4.2 \%(38 / 912)$ & $2.9 \%(17 / 596)$ & $4.9 \%(14 / 284)$ & 0.2537 \\
\hline Mal presentation & $1.4 \%(13 / 9 \mid 2)$ & $13.3 \%(79 / 596)$ & $18.0 \%(5 \mid / 284)$ & $<0.0001$ \\
\hline Preterm delivery & $5.0 \%(46 / 9 / 2)$ & $18.5 \%(110 / 596)$ & $30.3 \%(86 / 284)$ & $<0.000$ I \\
\hline PPROM & $0.2 \%(2 / 9 \mid 2)$ & $0.8 \%(5 / 596)$ & I.4\% (4/284) & 0.0561 \\
\hline Arrest of Ist stage of labor & $0.0 \%(0 / 912)$ & $0.0 \%(0 / 596)$ & $14.1 \%(40 / 284)$ & $<0.0001$ \\
\hline Arrest of $2 n d$ stage of labor & $0.8 \%(7 / 9 \mid 2)$ & $0.0 \%(0 / 596)$ & $1.1 \%(3 / 284)$ & 0.0694 \\
\hline Arrest of Ist or 2 nd stage of labor & $0.8 \%(7 / 9 \mid 2)$ & $0.0 \%(0 / 596)$ & $15.1 \%(43 / 284)$ & $<0.0001$ \\
\hline NRFHR & $1.2 \%(|1 / 9| 2)$ & $0.0 \%(0 / 596)$ & $4.2 \%(12 / 284)$ & $<0.000$ I \\
\hline Prolapse of cord & $0.0 \%(0 / 9 \mid 2)$ & $0.0 \%(0 / 596)$ & $1.8 \%(5 / 284)$ & $<0.0001$ \\
\hline Placenta previa & $0.1 \%(1 / 912)$ & $1.7 \%(10 / 596)$ & $0.4 \%(1 / 284)$ & 0.0010 \\
\hline Uterine rupture & $0.0 \%(0 / 9 \mid 2)$ & $0.3 \%(2 / 596)$ & $0.7 \%(2 / 284)$ & 0.0697 \\
\hline
\end{tabular}

Abbreviations: PET, preeclampsia; GDM, gestational diabetes; PROM, prelabor rupture of membranes; PPROM, preterm prelabor rupture of membranes; NRFHR, non reassuring fetal heart rate. 
Table S5 Peri-partum complications in the fourth delivery after primary CS

\begin{tabular}{|c|c|c|c|c|}
\hline Measure & $\begin{array}{l}\text { VBAC } \\
(N=5 \mid 4)\end{array}$ & $\begin{array}{l}\text { Elective CS } \\
(N=256)\end{array}$ & $\begin{array}{l}\text { Urgent CS } \\
(N=156)\end{array}$ & $P$-value \\
\hline Mild PET & $3.3 \%(17 / 5 \mid 4)$ & $0.4 \%(1 / 256)$ & $1.9 \%(3 / 156)$ & 0.0358 \\
\hline Severe PET & $0.6 \%(3 / 5 \mid 4)$ & $0.0 \%(0 / 256)$ & $6.4 \%(10 / 156)$ & $<0.000$ I \\
\hline Chronic hypertension & $1.6 \%(8 / 5 \mid 4)$ & $3.1 \%(8 / 256)$ & $5.8 \%(9 / 156)$ & 0.0155 \\
\hline GDM class $A$ & $5.1 \%(26 / 514)$ & $6.6 \%(17 / 256)$ & $5.8 \%(9 / 156)$ & $0.665 I$ \\
\hline GDM class B-R & I.4\% (7/5|4) & $4.7 \%(12 / 256)$ & $3.2 \%(5 / 156)$ & 0.0206 \\
\hline Hydramnios & $2.1 \%(|I / 5| 4)$ & $5.1 \%(13 / 256)$ & $7.7 \%(12 / 156)$ & 0.0037 \\
\hline Olihydramnios & $1.4 \%(7 / 5 \mid 4)$ & $0.4 \%(1 / 256)$ & $1.9 \%(3 / 156)$ & 0.3267 \\
\hline PROM & $6.8 \%(35 / 5 \mid 4)$ & $2.3 \%(6 / 256)$ & $6.4 \%(10 / 156)$ & 0.0327 \\
\hline Mal presentation & $1.4 \%(7 / 5 \mid 4)$ & II.3\% (29/256) & $13.5 \%(2|/| 56)$ & $<0.0001$ \\
\hline Preterm delivery & $7.6 \%(39 / 5 \mid 4)$ & $27.0 \%(69 / 256)$ & $24.4 \%(38 / I 56)$ & $<0.0001$ \\
\hline PPROM & $1.8 \%(9 / 5 \mid 4)$ & $0.8 \%(2 / 256)$ & $1.9 \%(3 / 156)$ & 0.5241 \\
\hline Arrest of Ist stage of labor & $0.0 \%(0 / 5 \mid 4)$ & $0.0 \%(0 / 256)$ & $\mid 3.5 \%(2|/| 56)$ & $<0.0001$ \\
\hline Arrest of 2 nd stage of labor & $0.6 \%(3 / 5 \mid 4)$ & $0.0 \%(0 / 256)$ & $1.9 \%(3 / 156)$ & 0.0595 \\
\hline Arrest of Ist or 2 nd stage of labor & $0.6 \%(3 / 5 \mid 4)$ & $0.0 \%(0 / 256)$ & $15.4 \%(24 / \mid 56)$ & $<0.0001$ \\
\hline NRFHR & $1.6 \%(8 / 5 \mid 4)$ & $0.0 \%(0 / 256)$ & $8.3 \%(13 / 156)$ & $<0.0001$ \\
\hline Prolapse of cord & $0.2 \%(1 / 514)$ & $0.0 \%(0 / 256)$ & $2.6 \%(4 / 156)$ & 0.0007 \\
\hline Placenta previa & $0.0 \%(0 / 5 \mid 4)$ & $2.3 \%(6 / 256)$ & $1.3 \%(2 / 156)$ & 0.0034 \\
\hline Uterine rupture & $0.0 \%(0 / 5 \mid 4)$ & $1.6 \%(4 / 256)$ & $0.6 \%(1 / 156)$ & 0.0202 \\
\hline
\end{tabular}

Abbreviations: PET, preeclampsia; GDM, gestational diabetes; PROM, prelabor rupture of membranes; PPROM, preterm prelabor rupture of membranes; NRFHR, non reassuring fetal heart rate.

Table S6 Perinatal outcome of first delivery after primary cesarean delivery according to the route of delivery

\begin{tabular}{|c|c|c|c|}
\hline Measure & VBAC N = 3622 & CS N = 3807 & $P$-value \\
\hline Male fetus & $49.9 \%(1806 / 3622)$ & $53.0 \%(2019 / 3807)$ & 0.007 \\
\hline SGA & $7.4 \%(267 / 3622)$ & $6.1 \%(23 \mid / 3807)$ & 0.026 \\
\hline LGA & $8.3 \%(301 / 3622)$ & $17.7 \%(674 / 3807)$ & $<0.001$ \\
\hline APD & $2.0 \%(73 / 3622)$ & $0.4 \%(15 / 3807)$ & $<0.001$ \\
\hline IPD & $0.1 \%(5 / 3622)$ & $0.0 \%(1 / 3807)$ & 0.116 \\
\hline PPD & $0.6 \%(2 \mathrm{I} / 3622)$ & $0.8 \%(32 / 3807)$ & 0.215 \\
\hline I minutes Apgar & $5.1 \%(186 / 3622)$ & $13.2 \%(502 / 3807)$ & $<0.001$ \\
\hline \multicolumn{4}{|l|}{ score $<5$} \\
\hline 5 minutes Apgar & $3.7 \%(135 / 3622)$ & $3.7 \%(142 / 3807)$ & 1.000 \\
\hline \multicolumn{4}{|l|}{ score $<7$} \\
\hline Birth weight(grams) mean \pm SD & $3129.2 \pm 569.0$ & $3|76.7 \pm 64| .3$ & $<0.001$ \\
\hline \multicolumn{4}{|l|}{ Birth weight (grams) } \\
\hline$<1500$ & $2.3 \%(82 / 3622)$ & $1.9 \%(74 / 3807)$ & $<0.00 \mathrm{I}$ \\
\hline $1500-2500$ & $6.7 \%(243 / 3622)$ & $9.7 \%(368 / 3807)$ & \\
\hline$>2500$ & $91.0 \%(3297 / 3622)$ & $88.4 \%(3365 / 3807)$ & \\
\hline \multicolumn{4}{|l|}{ Gestational age at delivery (weeks) } \\
\hline$<28$ & $1.0 \%(38 / 3622)$ & $0.5 \%(19 / 3807)$ & $<0.00$ I \\
\hline $28-32$ & $1.0 \%(37 / 3622)$ & $1.5 \%(59 / 3807)$ & \\
\hline $32-37$ & $6.1 \%(220 / 3622)$ & $9.7 \%(369 / 3807)$ & \\
\hline$>37$ & $91.9 \%$ (3327/3622) & $88.3 \%(3360 / 3807)$ & \\
\hline
\end{tabular}

Abbreviations: SGA, small for gestational age; LGA, large for gestational age; APD, ante partum death; IPD, intrapartum death; PPD, postpartum death. 
Table S7 Neonatal complications in patients with consecutive CS

\begin{tabular}{|c|c|c|c|c|}
\hline Complications & $\operatorname{CS}^{* 2}(n=3807)$ & $C^{*} 3(n=1387)$ & CS $^{*} 4(n=504)$ & CS*5 $(n=168)$ \\
\hline APD & $15(0.4 \%)$ & $18(1.1 \%)$ & 0 & $2(1.2 \%)$ \\
\hline PPD & $32(0.8 \%)$ & I $(0.6 \%)$ & $4(0.8 \%)$ & $6(3.6 \%)$ \\
\hline IPD & I (0.03\%) & $\mathrm{I}(0.1 \%)$ & 0 & 0 \\
\hline All mortality & $48(1.3 \%)$ & $27(2.0 \%)$ & $4(0.8 \%)$ & $8(4.8 \%)$ \\
\hline Apgar score at I minute $<5$ & $502(13.2 \%)$ & $140(10.1 \%)$ & $43(8.5 \%)$ & $26(15.5 \%)$ \\
\hline Apgar score at 5 minutes $<7$ & $142(3.7 \%)$ & $51(3.7 \%)$ & $12(2.4 \%)$ & 14 (8.3\%) \\
\hline Birthweight & $3176.7 \pm 641.3$ & $3021.4 \pm 596.0$ & $2952.5 \pm 538.9$ & $2903.4 \pm 510.4$ \\
\hline SGA & $231(6.1 \%)$ & $8 \mathrm{I}(5.8 \%)$ & $28(5.6 \%)$ & II (6.6\%) \\
\hline LGA & $674(17.7 \%)$ & $210(15.1 \%)$ & $58(\mathrm{II} .5 \%)$ & $19(11.3 \%)$ \\
\hline Gestational age at delivery (mean \pm S.D.) & $38.5 \pm 2.5$ & $37.5 \pm 2.1$ & $37.2 \pm 2.1$ & $36.8 \pm 3.1$ \\
\hline
\end{tabular}

Abbreviations: SGA, small for gestational age; LGA, large for gestational age; APD, ante partum death; IPD, intrapartum death; PPD, postpartum death; S.D., standard deviation.

Table S8 Neonatal complications in patients with consecutive VBAC

\begin{tabular}{|c|c|c|c|c|}
\hline Complications & VBAC $* 2(n=3622)$ & $\operatorname{VBAC} * 3(n=1721)$ & VBAC $* 4(n=88 I)$ & VBAC $* 5(n=506)$ \\
\hline APD & $73(2.0 \%)$ & $9(0.7 \%)$ & $9(1.0 \%)$ & $5(1.0 \%)$ \\
\hline PPD & $21(0.8 \%)$ & II (0.6\%) & $4(0.5 \%)$ & 0 \\
\hline IPD & $5(0.1 \%)$ & I (0.1\%) & I (0.1\%) & 0 \\
\hline All mortality & $99(2.7 \%)$ & $31(1.8 \%)$ & $14(1.6 \%)$ & $5(1.0 \%)$ \\
\hline Apgar score at I minute $<5$ & $186(5.4 \%)$ & $70(4.1 \%)$ & $36(4.1 \%)$ & 27 (5.3\%) \\
\hline Apgar score at 5 minutes $<7$ & $135(3.7 \%)$ & $61(3.5 \%)$ & $30(3.4 \%)$ & $24(4.7 \%)$ \\
\hline Birthweight & $3129.2 \pm 569.0$ & $3187.0 \pm 541.0$ & $3215.9 \pm 510.2$ & $3224.0 \pm 518.0$ \\
\hline SGA & $267(7.4 \%)$ & $114(6.6 \%)$ & $61(6.9 \%)$ & $39(7.7 \%)$ \\
\hline LGA & $30 \mathrm{I}(8.3 \%)$ & $189(11.0 \%)$ & $92(10.4 \%)$ & $72(14.2 \%)$ \\
\hline Gestational age at delivery (mean \pm S.D.) & $39.1 \pm 2.5$ & $39.3 \pm 2.3$ & $39.5 \pm 2.0$ & $39.4 \pm 2.1$ \\
\hline
\end{tabular}

Abbreviations: SGA, small for gestational age; LGA, large for gestational age; APD, ante partum death; IPD, intrapartum death; PPD, postpartum death; S.D., standard deviation.

\section{Publish your work in this journal}

The International Journal of Women's Health is an international, peerreviewed open-access journal publishing original research, reports, reviews and commentaries on all aspects of women's healthcare including gynecology, obstetrics, and breast cancer. Subject areas include: Chronic conditions (migraine headaches, arthritis, osteoporosis);

\section{Dovepress}

Endocrine and autoimmune syndromes; Sexual and reproductive health; Psychological and psychosocial conditions. The manuscript management system is completely online and includes a very quick and fair peer-review system. Visit http://www.dovepress.com/ testimonials.php to read real quotes from published authors. 